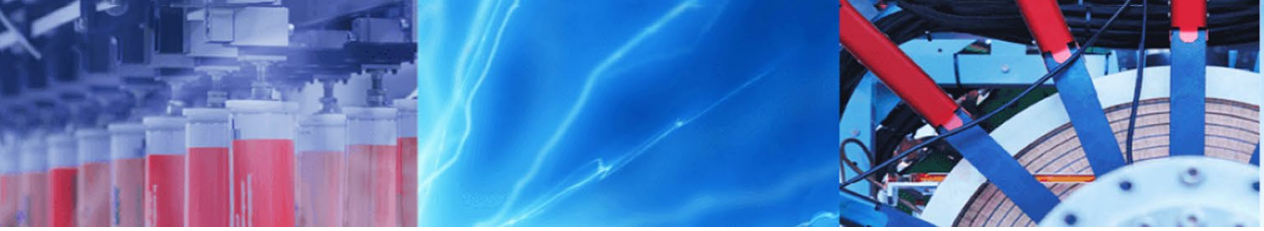

Research Article

\title{
Composite films of ecofriendly lignocellulosic nanostructures in biodegradable polymeric matrix
}

\author{
Clara R. Bauli ${ }^{1}$. Daniel B. Rocha ${ }^{1}$. Derval dos Santos Rosa ${ }^{1}$ (D)
}

(c) Springer Nature Switzerland AG 2019

\begin{abstract}
Cellulose nanostructures (CNS) are an alternative for reinforcement of biodegradable polymers. However, the usual process applied to obtain them is environmentally harmful, generating chemical wastes, mostly in the lignin removal process. In this work, bionanocomposites reinforced with CNS were obtained using a process with lower environmental impact, viz. enzymatic hydrolysis of Pinus wood, with or without alkaline pretreatment for lignin removal. They were then incorporated into poly(butylene adipate-co-terephthalate) (PBAT) at 1\%, 3\%, and 5\% (wt./wt.) by a solvent casting process with a nonionic surfactant as surface modification agent. The properties of the obtained composites indicated that pretreatment for lignin removal was not necessary to improve the mechanical properties. The isolated nature of the CNS led to a better distribution in the casting process and similar mechanical properties, with an increase in the Young's modulus by $16 \%$. Addition of the surfactant helped improve the dispersion of the reinforcement but did not affect the mechanical properties. The interaction with water was affected by the addition of surfactant, which resulted in a hydrophilic composite and influenced its post-use degradation. The results of this work confirm that it is possible to produce CNS composites without excessive consumption of reagents and that their properties can be modified for use in different packaging applications.
\end{abstract}

Keywords Nanocellulose $\cdot$ Lignocellulosic residue $\cdot$ Biodegradable polymers

\section{Introduction}

The use of polymeric materials has become increasingly dominant in the production of different industrial products, mainly due to their low cost and the possibility to control their thermal and mechanical properties [1]. However, a significant part of these products are designed for rapid disposal, what has caused concern in several sectors of society because of their strong resistance to environmental degradation and occupation of large volumes, where they remain for years until complete degradation [2]. Use of biodegradable polymers is an alternative to this scenario. According to ISO, "biodegradable polymers are materials that undergo significant chemical change by the action of microorganisms or enzymes releasing gases, water, salts and new biomass in a relatively short time of degradation" [3].

Among biodegradable polymers, poly(butylene adipate-co-terephthalate) (PBAT) is a synthetic aliphatic-aromatic polyester which displays mechanical properties similar to those of low-density polyethylene (LDPE). It is composed of poly(butylene adipate) (PBA), which is responsible for its flexibility, and poly(butylene terephthalate) (PBT), which confers rigid domains. PBAT offers high flexibility, low processing temperature, and the advantage of biocompatibility, being attractive for packaging and biomedical applications, as well as agricultural mulching films. However, some of its properties, e.g., its thermal and

Derval dos Santos Rosa, dervalrosa@yahoo.com.br | ${ }^{1}$ Environmentally Friendly Polymers Laboratory - Engineering, Modeling and Applied Social Sciences Center (CECS), Federal University of ABC (UFABC), Av. dos Estados 5001, Bairro Santa Terezinha, Santo André, SP 09210-580, Brazil.

SN Applied Sciences (2019) 1:774 | https://doi.org/10.1007/s42452-019-0765-0 
mechanical resistance, are lower than those of other polymers that are typically applied. Cellulose nanostructures can be used to address the cited problems [4].

Nanocelluloses are nanometric structures with large surface area and good mechanical properties, combining high elastic modulus (around $140 \mathrm{GPa}$ ) and tensile strength (up to $7500 \mathrm{MPa}$ ), low toxicity, and biodegradability. Use of the combination of PBAT and nanocellulose can overcome the limitations of the polymer matrix, creating a nanocomposite with improved properties [5]. Zhang et al. [6] reported that incorporation of $0.5 \%$ acetylated nanocellulose into PBAT tripled the modulus of elasticity of the material and increased its loss modulus by almost $20 \%$, with slight improvements in the thermal stability.

However, the high hydrophilicity and intramolecular bonds of cellulose make its dispersion in polymer matrices a challenge, leading to a decrease of the stress transfer between the phases and consequently reducing desired properties [7]. Literature describes efforts towards compatibilization of cellulose nanostructures [8-10]. Among these approaches, chemical modification of cellulose nanostructures is the predominant method, along with different strategies for drying and processing [11]. De Lima et al. [12] studied chemical modification of the nanocellulose surface with polyethylene glycol (PEG), an environmentally friendly polymer, to improve its stability in aqueous medium. Adsorption of surfactants onto the nanocellulose surface is another attractive alternative that has been studied recently $[13,14]$. Cellulose has a large number of hydroxyl groups in its structure, which allows intermolecular hydrogen bonds with amphiphilic molecules, in turn enabling interaction with nonpolar materials $[11,15,16]$.

Nonionic surfactants are already widely marketed products and represent a viable alternative for more complex surface modifications of cellulose nanostructures [13]. Heux et al. [17] were among the first to publish a technique using a nonionic surfactant, containing alkylphenol branches, to modify cellulose nanocrystals. The surfactant covered the crystals, forming a thin layer and ensuring their good dispersion in nonpolar solvents. Pinheiro et al. [18] modified nanocellulose using octadecyl isocyanate and observed an increase in the elasticity modulus of PBAT (+22 MPa) on incorporation of 7\% (wt./wt.) nanostructures. Moreover, Luzi et al. [19] studied the use of a commercial surfactant (acid phosphate ester of ethoxylated nonylphenol) for modification of cellulose; incorporation of $1 \%$ (wt./ wt.) into polylactic acid (PLA) resulted in improvements in the thermal stability, tensile strength, and vapor permeability of the matrix. However, such surface modification of CNS using a surfactant and the resulting improvements in the performance of the composite material depend on the interaction between the phases, which is affected by the surface charge of the nanostructures [13,
20-24]. Therefore, it is necessary to study such interactions specifically.

In this work, incorporation of nanostructures obtained from biomass residue (wood flour) into PBAT was studied, with or without the use of a nonionic surfactant. The nanostructures were obtained by enzymatic hydrolysis, which does not modify the surface charge [25]. Whether the usual removal of recalcitrant elements from wood flour is necessary to obtain suitable composites was also evaluated. Production of CNS without pretreatment is an environmentally friendly process, saving consumables and energy and reducing generation of residues [26], representing an attractive option to achieve reinforcement of bionanocomposites.

\section{Experimental}

\subsection{Materials}

The lignocellulosic residue used in this work was Pinus taeda sawdust, milled from transportation pallet waste supplied by local companies. Poly(butylene adipate-coterephthalate) (PBAT) was Ecoflex ${ }^{\oplus}$, produced and supplied by BASF (Germany) and having average molecular mass weight of $66,500 \mathrm{~g} \mathrm{~mol}^{-1}$. Enzyme complexes $\mathrm{CTec} 2^{\circledR}$ and $\mathrm{HTec}^{\circledast}$ were supplied by Novozymes (USA). Nonionic surfactant Ultraric PE $105^{\circledR}$ (EO-PO copolymer) was supplied by Oxiteno (Brazil). Calcium hypochlorite, chloroform, and sodium hydroxide were purchased from Labsynth Laboratory Products (Brazil), while acetic acid, sodium citrate, and hydrogen peroxide were purchased from Casa Americana Laboratory Products (Brazil). All reagents were used without further purification.

\subsection{Preparation of cellulose nanostructures}

Lignocellulosic residue (Pinus taeda sawdust) smaller than 50 mesh was separated into two groups, pretreated and non-pretreated; their preparation was reported previously [26]. Two alkaline steps were applied for pretreatment of the former residue: application of solution of calcium hypochlorite $1 \%$ (wt./wt.) and acetic acid 1\% (v/v) at $70^{\circ} \mathrm{C}$ for $1 \mathrm{~h}$ for removal of waxes and fiber exposure, and bleaching in solution of hydrogen peroxide $24 \%(\mathrm{v} / \mathrm{v})$ and sodium hydroxide $4 \%$ (wt./v) at $50{ }^{\circ} \mathrm{C}$ for $2 \mathrm{~h}$. The second step was repeated three times for better results.

Nanocellulose structures were then obtained by applying commercial enzyme complexes $\mathrm{CTec}^{\circledR}$ and $\mathrm{HTec}^{\circledR}$ for $48 \mathrm{~h}$ in sodium citrate buffer solution $(50 \mathrm{mM})$ at $50^{\circ} \mathrm{C}$. This process was applied to both the pretreated and nonpretreated samples. The resulting solutions were heated to $100{ }^{\circ} \mathrm{C}$ for enzyme denaturation [26]. The nanostructures 
were centrifuged for $15 \mathrm{~min}$ at $10^{\circ} \mathrm{C}$ and $16,000 \mathrm{rpm}$, and the supernatant volume was removed and replaced with distilled water to remove the buffer solution; this process was repeated three times. The nanostructures obtained after pretreatment are called $\mathrm{P}$ samples, while those with no pretreatment are called $\mathrm{N}$ samples.

\subsection{Preparation of bionanocomposites}

Both nanostructures ( $\mathrm{P}$ and $\mathrm{N}$ ) were incorporated into PBAT by a solvent casting method. The nanostructures were dispersed in chloroform after solvent exchange with an intermediate step in acetone [27]. The nanostructures were centrifuged for $15 \mathrm{~min}$ at $10^{\circ} \mathrm{C}$ and $16,000 \mathrm{rpm}$. The supernatant volume was replaced with acetone and sonicated for $1 \mathrm{~min}$ at $92 \mathrm{~kJ}$. The obtained acetone-water solution was centrifuged for $25 \mathrm{~min}$ at $10^{\circ} \mathrm{C}$ and $16,000 \mathrm{rpm}$. The supernatant volume (water) was then replaced with chloroform and sonicated for $1 \mathrm{~min}$ at $92 \mathrm{~kJ}$. The chloroform-acetone system was centrifuged for $25 \mathrm{~min}$ at $10^{\circ} \mathrm{C}$ and $16,000 \mathrm{rpm}$. The supernatant volume (acetone) was removed, resulting in CNS chloroform solution.

To produce composites, PBAT chloroform solution was prepared with $8 \%$ (wt./v.) concentration, being mechanically stirred until complete dissolution. CNS and PBAT solution in chloroform were mixed at CNS/PBAT proportions of $1 \%, 3 \%$, and $5 \%$ (wt./wt.), then stirred mechanically for $1 \mathrm{~h}$. The resultant mixtures were placed in petri dishes to dry at room temperature for $24 \mathrm{~h}$.

To evaluate the possibility of promoting the interfacial interaction between the phases, nonionic surfactant Ultraric $\mathrm{PE}^{\circledast}$ was used in 1:4 proportion (surfactant:fiber). The compound was added to the CNS chloroform solution and stirred mechanically for $1 \mathrm{~h}$. The samples with the surfactant (identified as SP and SN samples for the pretreated and non-pretreated case, respectively) were then used to produce composite films using the process cited above. Table 1 presents the nomenclature and composition of the produced samples.

\subsection{Characterization of Materials}

The size of the nanostructures, quantified as the hydrodynamic radius $\left(R_{H}\right)$, was evaluated by dynamic light scattering (DLS, ALV-CGS3; ALV, Germany) with detector angle of $90^{\circ}$. The mechanical proprieties of the films were determined according to ASTM D882-18 (Tryton 250; MTS, USA) using a $100-\mathrm{N}$ load cell at claw speed of $50 \mathrm{~mm} / \mathrm{min}$. Thermogravimetric analysis (TGA 4000; PerkinElmer, USA) was performed at a rate of $20^{\circ} \mathrm{C} / \mathrm{min}$ in inert nitrogen atmosphere. The contact angle was measured (Phoenix 300 Touch; Surface \& Electro-Optics-SEO, South Korea) with automatic control of droplet volume based on hysteresis
Table 1 Nomenclature of composite samples produced using two different nanostructure cellulose reinforcements and their modifications

\begin{tabular}{llll}
\hline Sample & $\begin{array}{l}\text { Pretreated CNS } \\
\text { (wt.\%) }\end{array}$ & $\begin{array}{l}\text { Non-pretreated } \\
\text { CNS (wt.\%) }\end{array}$ & Surfactant \\
\hline PBAT & 0 & 0 & No \\
P1\% & 1 & - & No \\
P3\% & 3 & - & No \\
P5\% & 5 & - & No \\
SP1\% & 1 & - & Yes \\
SP3\% & 3 & - & Yes \\
SP5\% & 5 & - & Yes \\
N1\% & - & 1 & No \\
N3\% & - & 3 & No \\
N5\% & - & 5 & No \\
SN1\% & - & 1 & Yes \\
SN3\% & - & 3 & Yes \\
SN5\% & - & 5 & Yes \\
\hline
\end{tabular}

measurement after $5 \mathrm{~min}$ in contact with the film surface. Water absorption was measured based on ASTM D57098 (2018) on samples with dimensions of $70 \times 5 \times 0.2 \mathrm{~mm}$ in triplicate. Simulated degradation was performed for 90 days in soil composed of $23 \%$ sand, $23 \%$ earth, $23 \%$ organic mass, and $31 \%$ distilled water. The samples were buried according to standard ASTM D5338-15 [28]. Optical microscopy was performed (Scope A1; Zeiss, Germany) at $100 \times$ magnification.

\section{Results and Discussion}

The obtained nanostructures were characterized and reported previously [26], confirming their nanocrystallike structure. The hydrodynamic radius $\left(R_{\mathrm{H}}\right)$ of the $\mathrm{P}$ and $\mathrm{N}$ samples in water (Fig. 1a) presented a single peak with a broad distribution centered at around $210 \mathrm{~nm}$ and $280 \mathrm{~nm}$, respectively. Such a broad distribution was predictable, since the enzymes were applied as complexes, acting in different phases of microcellulose breakage and having different access to the substrate, leading to particles of different sizes [29].

DLS analysis was used to estimate the size of the structures in chloroform (Fig. 1b, c), to evaluate the structures for film production. The $R_{H}$ of $\mathrm{P}$ sample increased to $511 \pm 12 \mathrm{~nm}$, due to particle agglomeration, since polar groups on the cellulose surface tend to interact with other CNS, an effect that decreases for nonpolar solvents [30, 31]. The $\mathrm{N}$ sample, however, did not present the same behavior; the size was not significantly affected by solvent exchange, which can be explained by the presence 


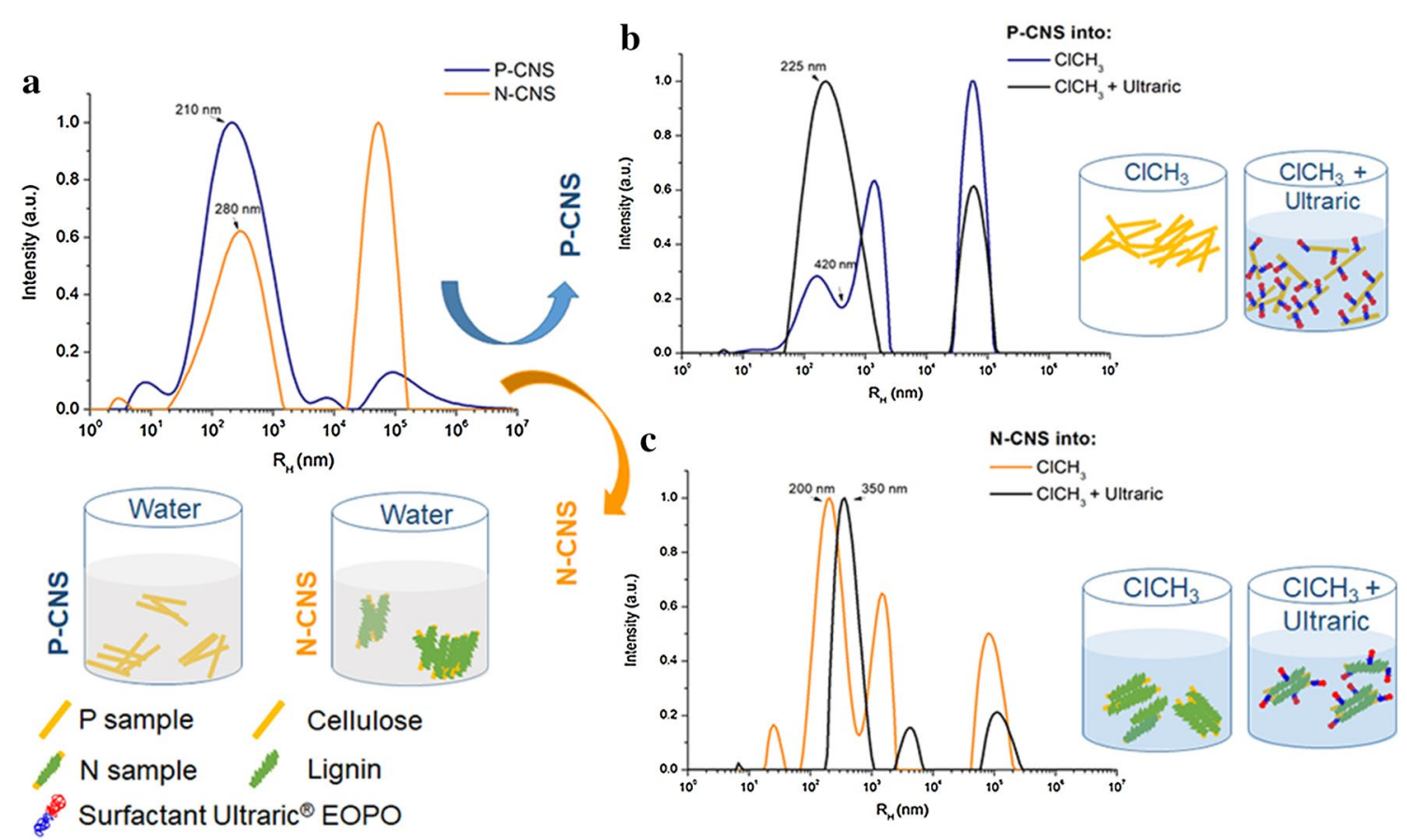

Fig. 1 Hydrodynamic radius of a P and N samples in water, $\mathbf{b} \mathrm{P}$ and $\mathrm{SP}$ in chloroform, and $\mathbf{c} \mathrm{N}$ and NP in chloroform. Schemes illustrate the expected distribution of nanostructures in each environment

of lignin from the original lignocellulosic material, which is partially soluble in chloroform [32].

Addition of surfactant to the nanostructure/chloroform reduced the mean $R_{\mathrm{H}}$ of SP sample back to $263 \pm 19 \mathrm{~nm}$, close to the value for isolated fibers in water, indicating that addition of the surfactant prevented agglomeration of the nanostructures. As described by Smith et al. and Fortunati et al. [33, 34], the surfactant acts as a dispersant, offering steric hindrance to particle approach. The hydrophobic tail can interact with nonpolar components, such as the polymeric matrix or organic solvents, while the hydrophilic part is adsorbed onto the surface of the nanoparticles [31]. The SN sample, however, exhibited the opposite effect, as the $R_{\mathrm{H}}$ increased to $394 \pm 14 \mathrm{~nm}$, being indicative of particle agglomeration. According to Agarwal et al. [35], nonionic surfactants can interact with lignin available on the surface of lignocellulosic compounds via their nonpolar tail, which can make the SN surface more hydrophilic than $\mathrm{N}$ particles, causing agglomeration in chloroform.

All the nanostructures (both pretreated and non-pretreated, with and without surfactant) were incorporated into PBAT matrix in proportions of $1 \%, 3 \%$, and $5 \%$ (wt./ wt.), resulting in cast films. The casting process is widely used to produce nanocomposites in literature; although its productivity is lower than other usual thermal methods such as extrusion, it avoids degradation during the process and allows production of oriented structures. Recently, several methods have been reported to improve the productivity of the casting method, e.g., continuous casting, which will reduce the difference from traditional methods $[36,37]$.

The mechanical properties of the composites are shown in Fig. 2.

The PBAT cast films presented properties similar to those reported in literature with elastic modulus of $51 \pm 0.4 \mathrm{MPa}$ and tensile strength of $6.2 \pm 0.1 \mathrm{MPa}$ [38]. Addition of the reinforcements resulted in different modifications. For the composites produced with $\mathrm{P}$ sample, addition of 1 or 3 wt.\% improved the elastic modulus by $11 \%$ and $12 \%$ and the tensile strength by $12 \%$ and $5 \%$, respectively. However, addition of $5 \mathrm{wt} . \%$ reduced the modulus by $10 \%$ and tensile strength by $33 \%$. These results indicate that reinforcement addition is advantageous up to $3 \mathrm{wt} . \%$, but further addition degrades the properties due to the tendency for agglomeration. Pinheiro et al. and EspinoPérez et al. $[18,39]$ observed similar results, with degradation of the properties with increasing reinforcement. Modification of the reinforcement surface (SP samples) did not change this behavior. It was observed that addition of 1 and $3 \mathrm{wt} . \%$ increased the elastic modulus by $4 \%$ and $15 \%$, while the sample with 5 wt.\% addition exhibited a reduction of $5 \%$. However, all the samples presented a reduction of the tensile strength, by $10 \%, 13 \%$, and $21 \%$ for the composites with 1,3 , and 5 wt.\% addition, respectively. These results indicate that addition of the nonionic 

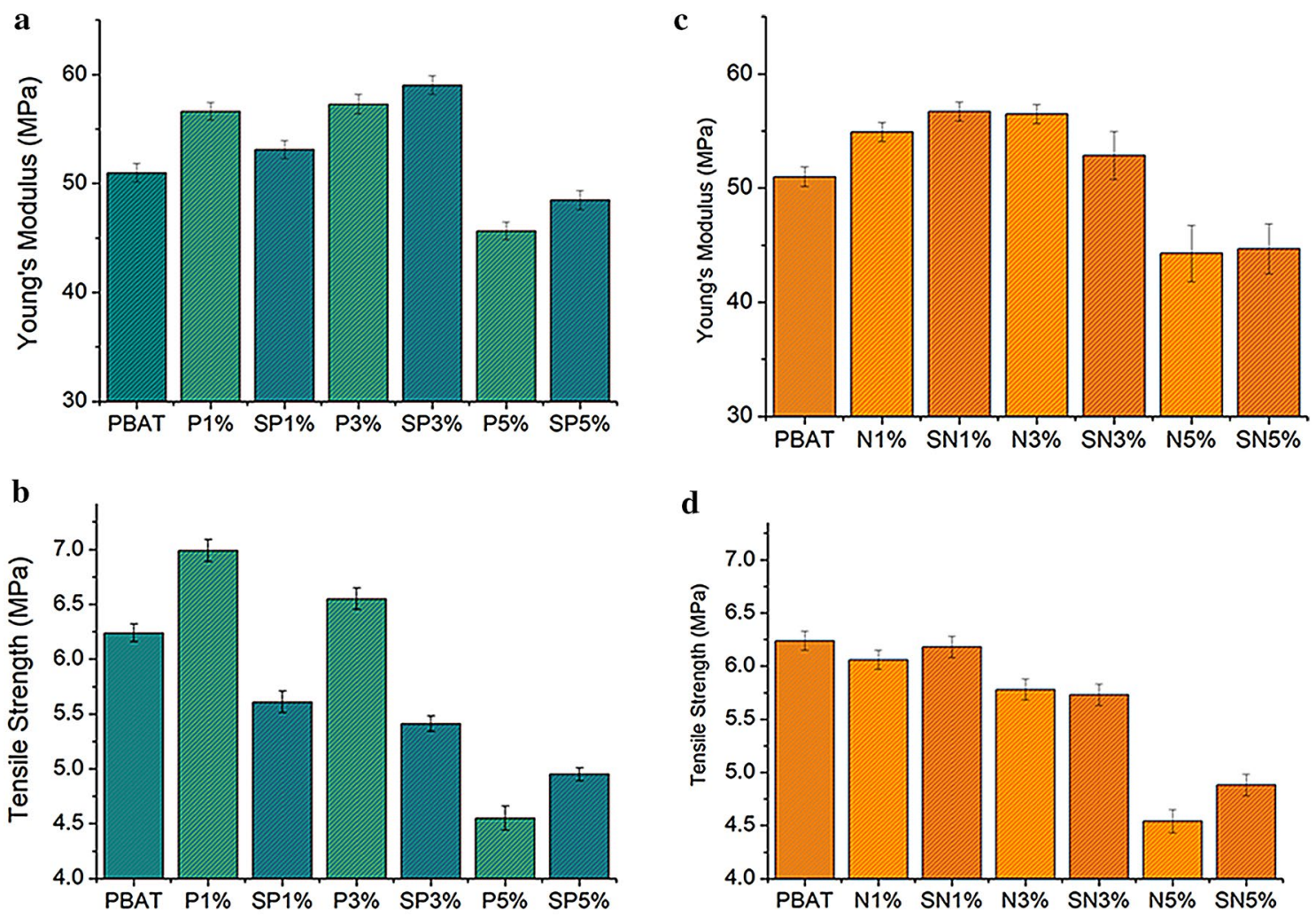

Fig. 2 a, c Young's modulus and $\mathbf{b}$, $\mathbf{d}$ tensile strength of PBAT films with incorporated $\mathbf{a}, \mathbf{b}$ P and $\mathbf{c}, \mathbf{d} \mathrm{N}$ samples, with and without surfactant

surfactant did not promote the interaction in the composites or improve the properties of these samples. This result was not expected [7], but may also be related to the excess surfactant in the composition, which could be dispersed in isolated form in the matrix, affecting the stress distributions [40].

For the composites with addition of 1 and $3 \mathrm{wt} . \% \mathrm{~N}$ sample, the elastic modulus increased by $8 \%$ and $11 \%$, while addition of $5 \%$ reduced this property by $13 \%$. The same behavior was observed for the pretreated samples. Also, increasing the concentration of reinforcement reduced the tensile strength. On addition of $1 \mathrm{wt} . \%$, the tensile strength was maintained, considering the error, compared with the neat matrix. However, addition of 3 and 5 wt.\% reduced this property by $7 \%$ and $27 \%$. The increase in the stiffness of these samples is related to the presence of lignin. As reported by Sudhakaran et al. [41], lignin may present an amphiphilic nature and promote the interaction with the polymeric matrix, in particular PBAT. The aromatic rings of lignin and PBAT can interact via hydrogen bonding, forming a $\pi-\pi$ complex and promoting adhesion between the phases [42].

The SN composites presented an increase of $11 \%$ and $4 \%$ in the elastic modulus for the samples with 1 and $3 \mathrm{wt} . \%$ addition, respectively. This indicates a decreasing trend after $3 \mathrm{wt} . \%$, as observed for the $5 \mathrm{wt} . \%$ composite, with a reduction of $12 \%$. The tensile strength reduced with a trend similar to that observed for the $\mathrm{N}$ sample, maintaining the value for $1 \mathrm{wt} . \%$ but showing reductions of $8 \%$ and $22 \%$ for 3 and $5 \mathrm{wt} . \%$, respectively.

Therefore, the properties of the composites tended to increase with small additions of reinforcement, viz. P1\% and $\mathrm{N} 1 \%$. The sample with no pretreatment represents an attractive option due to its similar behavior to those with traditional pretreatment. Addition of the surfactant did not improve the properties, suggesting an ineffective impact on the mechanical properties [40].

The thermal stability of the PBAT composites was also evaluated. The thermal degradation of the films with $1 \mathrm{wt} . \%$ reinforcement is shown in Fig. 3. For the neat matrix, the degradation onset temperature $\left(T_{10 \%}\right)$, taken at a loss of $10 \%$ of the composite weight, was $407^{\circ} \mathrm{C}$, while the maximum degradation temperature $\left(T_{\max }\right)$, measured by differential thermogravimetry (DTG), was $429^{\circ} \mathrm{C}$; similar values were also found by Mukherjee et al. [43]. Incorporation of the cellulose nanostructures as reinforcement did not significantly modify the degradation onset temperature, but did modify the maximum degradation temperature. Table 2 presents the thermal stability values for the composites.

The composites with addition of $3 \mathrm{wt} . \%$ nanostructures presented the best results. P3\% showed an improvement 

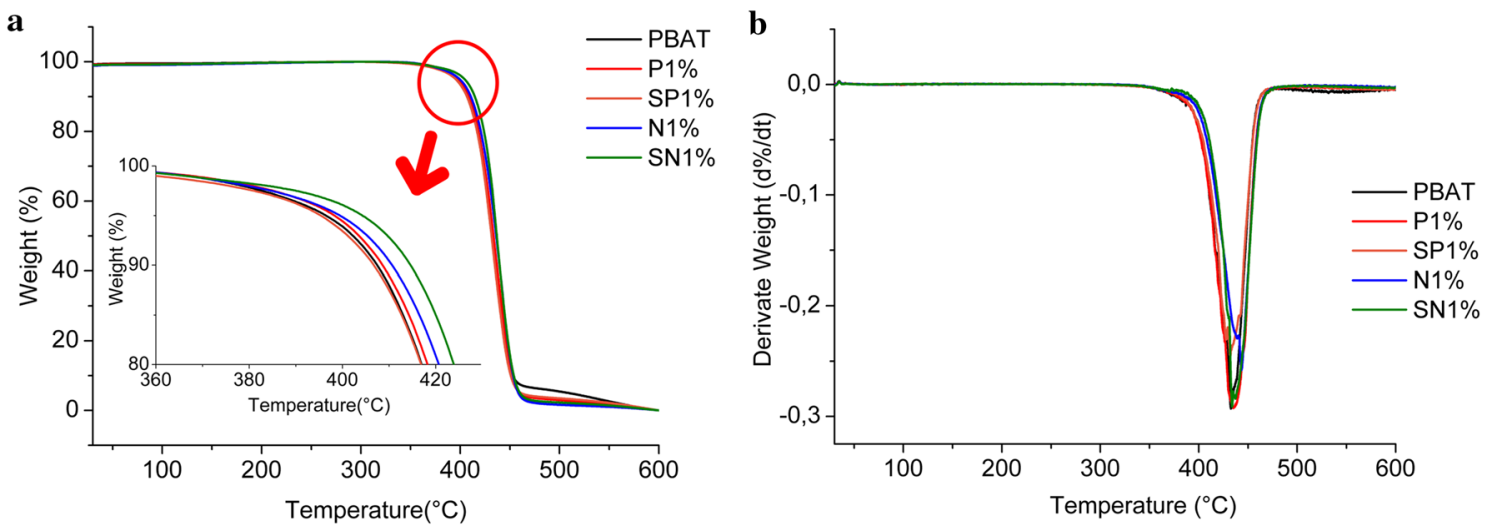

Fig. 3 Thermal degradation curves, showing the mass loss of the composites with incorporation of 1 wt.\% P, N, SP, and SN samples

Table 2 Temperature for $10 \%$ mass loss of the composite $\left(T_{10}\right)$ and the temperature of the maximum rate of degradation $\left(T_{\max }\right)$

\begin{tabular}{llllll}
\hline Sample & $T_{10 \%}\left({ }^{\circ} \mathrm{C}\right)$ & $T_{\max }\left({ }^{\circ} \mathrm{C}\right)$ & Sample & $T_{10 \%}\left({ }^{\circ} \mathrm{C}\right)$ & $T_{\max }\left({ }^{\circ} \mathrm{C}\right)$ \\
\hline PBAT & 407 & 429 & Ultraric & 344 & 410 \\
P1\% & 409 & 434 & N1\% & 407 & 440 \\
P3\% & 416 & 442 & N3\% & 410 & 440 \\
P5\% & 409 & 438 & N5\% & 412 & 434 \\
SP1\% & 407 & 429 & SN1\% & 415 & 435 \\
SP3\% & 410 & 434 & SN3\% & 410 & 429 \\
SP5\% & 412 & 430 & SN5\% & 410 & 430 \\
\hline
\end{tabular}

of $13{ }^{\circ} \mathrm{C}$ in $T_{\text {max }}$ while $\mathrm{N} 3 \%$ showed $11^{\circ} \mathrm{C}$. However, the composites with surfactant presented lower temperatures of maximum degradation, in comparison with the composites without surfactant. The surfactant has a lower molecular weight than the matrix, and thus poorer thermal resistance, as presented in Table 2 [44]. The $T_{\max }$ of the surfactant was at around $410^{\circ} \mathrm{C}$, above that of the matrix. SP3\% sample presented an improvement of only $5^{\circ} \mathrm{C}$, while SN $1 \%$ presented a degradation temperature $6{ }^{\circ} \mathrm{C}$ higher than that of the matrix. In any case, the addition of reinforcement was positive in terms of the thermal stability, and like the mechanical properties, lower reinforcement concentration provided better results; Khoo et al. observed similar behavior on addition of $1 \%$ to $5 \%$ cellulose nanostructures to PLA matrix [45]. Even without modification, the adhesion to the matrix influenced the thermal proprieties of the composites, making the groups without surfactant more attractive [46]. The thermal stability results indicated that thermal reprocessing would be possible, allowing recycling of such films to obtain new raw materials, although the effects of chain scission and the reinforcement dispersion could lead to degraded properties compared with the original cast composite $[47,48]$.

To evaluate the degradation properties, the interaction with water was also measured, since the degradation process starts with hydrolysis, as reported by Macedo et al. [49]. The contact angle can be used to evaluate the wettability of a sample surface, while its hysteresis evaluates the behavior of water on the surface after a short period [50, 51]. The contact angle and hysteresis values are shown in Fig. 4. The contact angle obtained for PBAT was $70.7 \pm 1.6^{\circ}$ with hysteresis of $7.45 \pm 1.28^{\circ}$, similar to literature values [52]. $\underline{\mathbf{a}}$

\begin{tabular}{cccccc}
\hline Sample & $\begin{array}{c}\text { Contact } \\
\text { Angle }\left(\theta^{\circ}\right)\end{array}$ & $\begin{array}{c}\text { Hysteresis } \\
\left(\Delta \theta^{\circ}\right)\end{array}$ & Sample & $\begin{array}{c}\text { Contact } \\
\text { Angle }\left(\theta^{\circ}\right)\end{array}$ & $\begin{array}{c}\text { Hysteresis } \\
\left(\Delta \theta^{\circ}\right)\end{array}$ \\
\hline N1\% & $77,2 \pm 1,5$ & $4,2 \pm 2,9$ & P1\% & $73,7 \pm 0,5$ & $3,5 \pm 0,2$ \\
N3\% & $71,1 \pm 0,8$ & $2,8 \pm 1,7$ & P3\% & $77,9 \pm 0,5$ & $2,2 \pm 1,1$ \\
N5\% & $75,0 \pm 0,5$ & $1,3 \pm 1,0$ & P5\% & $79,1 \pm 0,2$ & $3,0 \pm 1,6$ \\
SN1\% & $46,2 \pm 3,4$ & $2,3 \pm 0,5$ & SP1\% & $60,1 \pm 3,7$ & $2,2 \pm 0,2$ \\
SN3\% & $46,5 \pm 2,7$ & $2,0 \pm 0,1$ & SP3\% & $64,3 \pm 3,4$ & $2,6 \pm 0,9$ \\
SN5\% & $43,5 \pm 2,6$ & $1,6 \pm 1,0$ & SP5\% & $64,4 \pm 2,6$ & $2,6 \pm 0,4$ \\
\hline
\end{tabular}

b

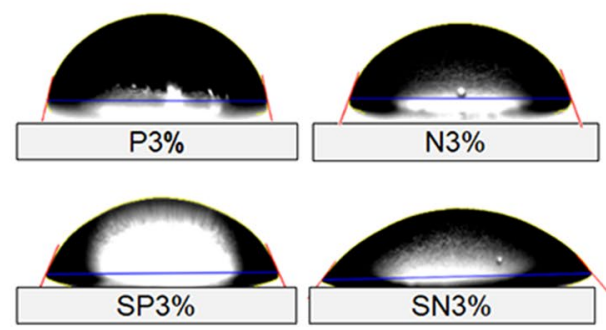

Fig. 4 a Contact angle and hysteresis measurements for composites and $\mathbf{b}$ experimental droplets for composites with 3 wt.\% CNS incorporation 
Addition of $\mathrm{P}$ and $\mathrm{N}$ nanostructures promoted an increase of the contact angle and, consequently, the hydrophobicity of the sample surface. However, the hysteresis was decreased, indicating a stable characteristic of the surface. For the $\mathrm{N}$ samples, an increase in the contact angle values was expected with increasing reinforcement concentration, since the presence of lignin promotes this effect, as reported by Rojo et al. [51], due to its more nonpolar characteristic. For $P$ samples, the increase was unexpected, since other reports indicated the opposite behavior [53]. However, as reported by Feng et al. [54], the reinforcement distribution also plays a role in the surface characteristics and consequently influences the contact angle [55].

Addition of the surfactant led to the opposite behavior. For SP samples, the values decreased by $10^{\circ}$ for the lower reinforcement loading and $6^{\circ}$ for the others. However, for $\mathrm{SN}$ samples, the values were even lower, presenting a reduction of $26^{\circ}$ for sample SN5\%. The surfactant was added to improve the interaction between the hydrophobic matrix and hydrophilic reinforcement, but due to its amphiphilic character, inversion was observed, as highlighted for the SN samples, promoting lower contact angle values. As described by Wang et al. [56], added nonionic surfactant tends to interact hydrophobically with lignin from lignocellulosic residues. This would promote the increase of the hydrophilicity of the particle surface, thus the same characteristic was reproduced on the sample surface, which also justifies the degradation of the mechanical properties due to the lower interaction between the phases. An increase of free surfactant in the matrix, i.e., not bonded to the reinforcement, as described by Solala et al. [57], can also reduce the contact angle of the sample.

Control of the wettability, besides degradation, is essential to determine the application of a material. The increase of hydrophobicity observed for $\mathrm{N}$ samples is desirable for use as food packaging, due to the improved barrier property against water and gases [42].

The water absorption was also measured, as it plays an essential role in the degradation process. The values of water absorbed are shown in Fig. 5, taken over 100 h. PBAT presented a mass gain of $3.5 \%$ in the equilibrium state, i.e., the value of maximum polymer swelling [58]. This value is higher than others reported in literature [28]. However, the casting process allows the formation of a porous structure and consequently induces higher absorption [59].

Addition of the reinforcements resulted in behavior similar to that observed for the contact angle. Addition of $\mathrm{P}$ sample and mainly $\mathrm{N}$ samples tended to reduce the water absorbed compared with the neat matrix. Samples
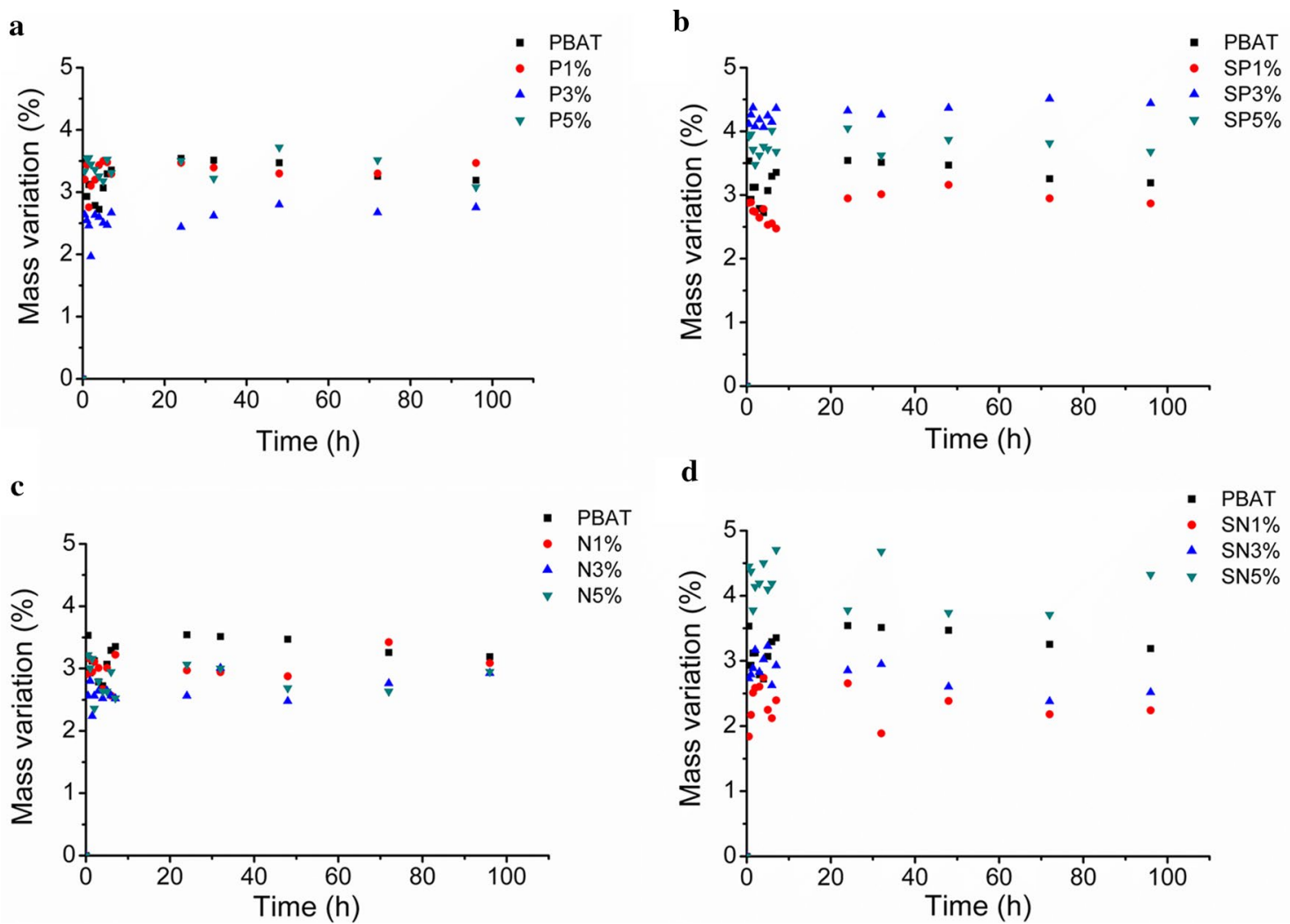

\section{d}

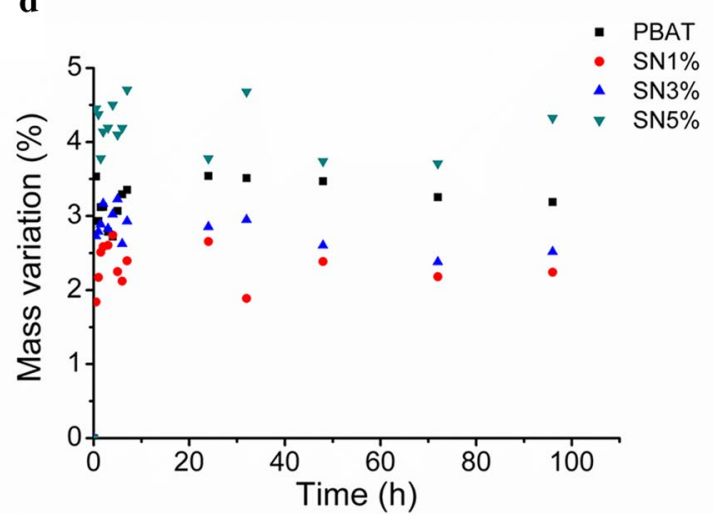

Fig. 5 Values of water absorption for composites containing a P, b SP, $\mathbf{c ~ N}$, and $\mathbf{d}$ SN samples 
P1\% and P5\% presented approximately the same value of maximum absorption, around $3.4 \%$. However, sample $\mathrm{P} 3 \%$ presented a reduction to $2.75 \%$. Addition of $\mathrm{N}$ samples reduced the values of absorption to $3.0 \%, 2.5 \%$, and $3.25 \%$ for samples N1\%, N3\%, and N5\%, respectively. This reduction follows the trend of the hydrophobicity for the lower reinforcement loads. However, the samples with higher reinforcement concentration presented higher absorption, probably due to particle agglomeration [54].

Addition of the surfactant increased the water absorption for samples with higher reinforcement concentrations, corroborating the contact angle measurements. The SP samples presented values of $3.0 \%, 3.75 \%$, and $4.25 \%$ for SP1\%, SP3\%, and SP5\%, respectively, while SN samples presented values of $2.75 \%, 3.25 \%$, and $4.75 \%$ for $\mathrm{SN} 1 \%$, SN3\%, and SN5\%, respectively. As reported by Liu et al. and Aramendia et al. [60,61], free surfactant, especially when nonionic, may form aggregates, which absorb water and increase the value of the absorption for the polymer.
Figure 6 shows an illustration of the expected interaction between the reinforcements and PBAT matrix in the obtained composites. For pretreated samples (Fig. 6a), the interaction between the matrix and nanostructure is positive. An increase in the mechanical and thermal properties was observed, although absorption also increased, indicating the presence of free spaces in the polymer and the formation of aggregates in the composite $[18,39]$. When the surfactant was added to the structure, the interaction was not promoted, and the mechanical properties were reduced [60]. For non-pretreated samples (Fig. 6b), the interaction was promoted, increasing the mechanical and thermal properties and reducing the water absorption, which indicates the formation of less free space in the polymer. For both $\mathrm{P}$ and $\mathrm{N}$ samples, increasing the reinforcement loading did not tend to improve the properties, due to agglomeration [41,51]. Also, Fig. $6 \mathrm{~b}$ shows the composites of $\mathrm{N}$ samples (1,3, and $5 \mathrm{wt} . \%)$, revealing the excellent transparency of the films with a modification

d
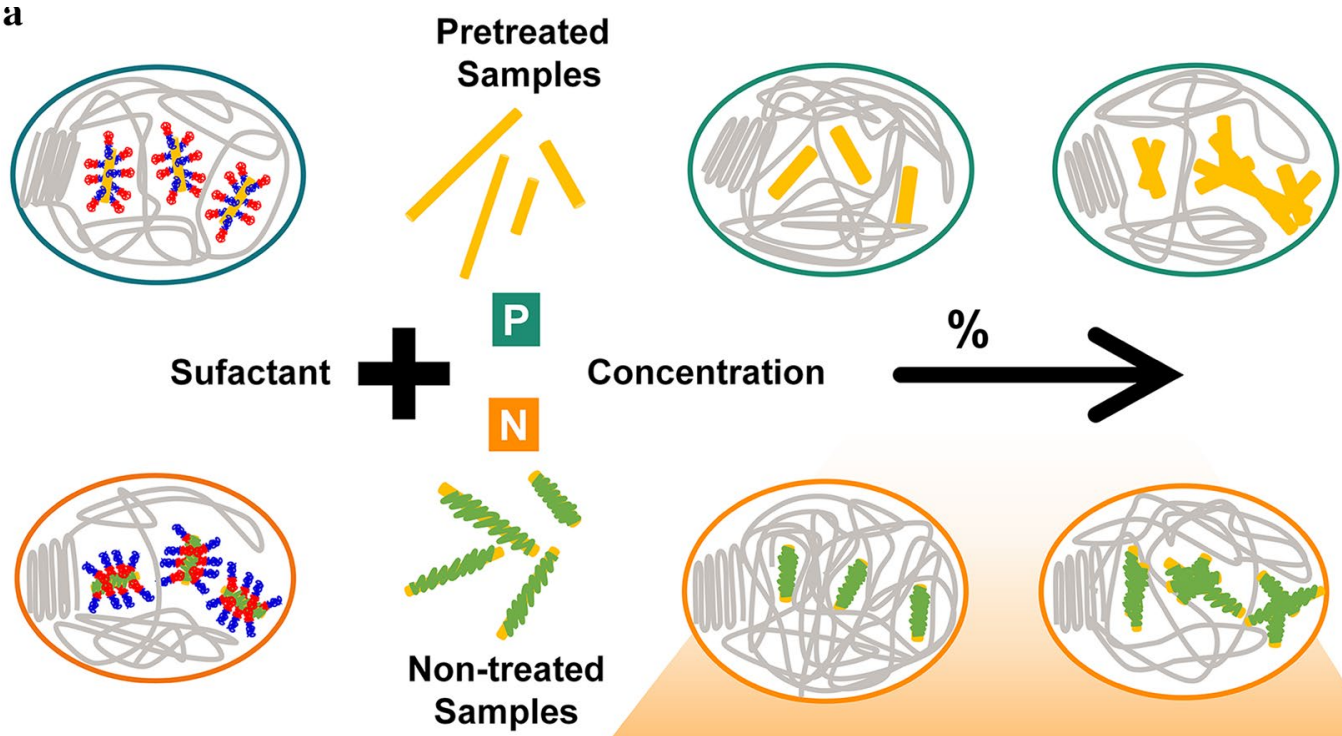

Concentration

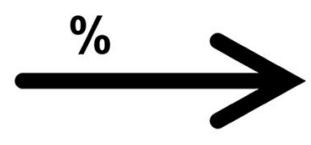

b

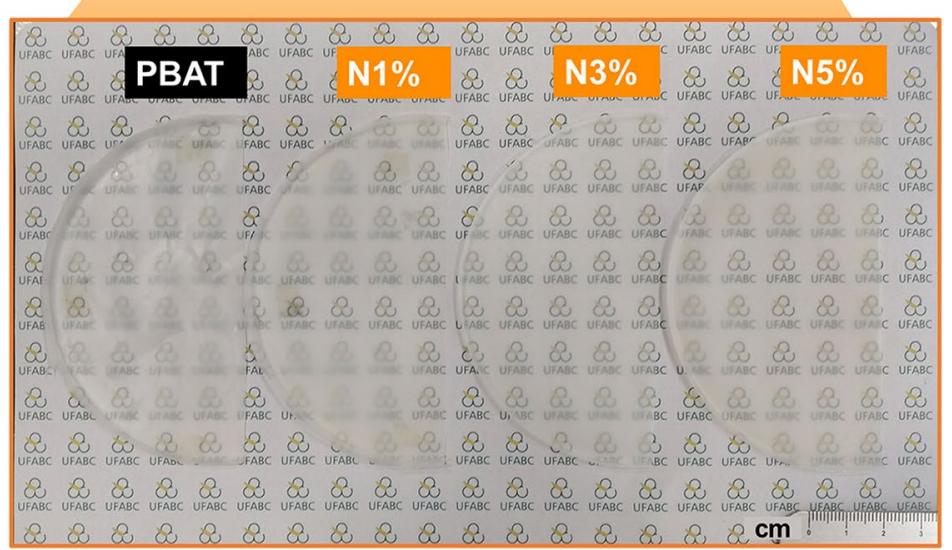

Fig. 6 a Schematic showing how particles interact with the polymeric matrix for $\mathrm{P}$ and $\mathrm{N}$ samples, considering the increase in concentration and addition of surfactant for both samples. b Composite samples containing 1, 3, and 5 wt.\% N samples 
of the color for the more concentrated samples, due to the presence of more reinforcement and agglomerates. The SN samples presented lower results than the non-pretreated sample, again indicating the inefficiency of the surfactant. The degraded results can be attributed to the interaction of the surfactant with the lignin of the reinforcement. It can interact with the nonpolar segment of the surfactant, generating inversion of the surface characteristic, resulting in a lower interaction with the polymer matrix $[56,57]$.

After evaluating the interaction of water with the samples, simulated degradation in soil was also evaluated. Several literature reports describe the degradation process of PBAT in compostable soils, revealing a significant influence on many characteristics such as the molecular weight, crystallinity, and wettability, as well as environmental effects such as temperature, humidity, and aeration level $[62,63]$. Figure 7 shows the mass loss of the samples during degradation over 90 days.

The obtained degradation curves indicate low mass loss during this process. Similar behavior was reported by Kijchavengkul et al. and Morelli et al. [38, 62]. This low degradation is expected as the simulated conditions are not those indicated by the polymer producer, which indicate constant aeration of the soil, elevated temperature, and high humidity environment, ideal conditions for composting plants. However, these conditions are not usual in most locations around the world [64]. The simulated soil degradation conditions applied in this work were to simulate post-use disposal in the environment.

The results indicate that $\mathrm{P}$ and $\mathrm{N}$ samples showed similar behavior during this period of degradation. For $\mathrm{P}$ samples, a usual mass gain was observed for $\mathrm{P} 1 \%$ and $\mathrm{P} 3 \%$, related to water absorption and the possible creation of a biolayer of microorganisms that act in biodegradation. However, as expected from the water absorption and contact angle experiments, the degradation of the composite was slower than that of the matrix; that is, the mass loss after the period was lower than for the matrix, with sample P5\% showing the closest value to neat PBAT. The N samples did not present a mass gain, but showed a behavior very similar to that of the matrix, with only sample N5\% presenting slightly higher degradation than neat PBAT. Slower degradation is related to lower water absorption in the composite $[38,65]$.

Addition of surfactant promoted a behavior more similar to that of the neat matrix than without its addition, also showing a higher mass loss. During the evaluated period, SP samples presented values close to the matrix, despite the absorption of water. The SN samples presented different behaviors, with the sample having
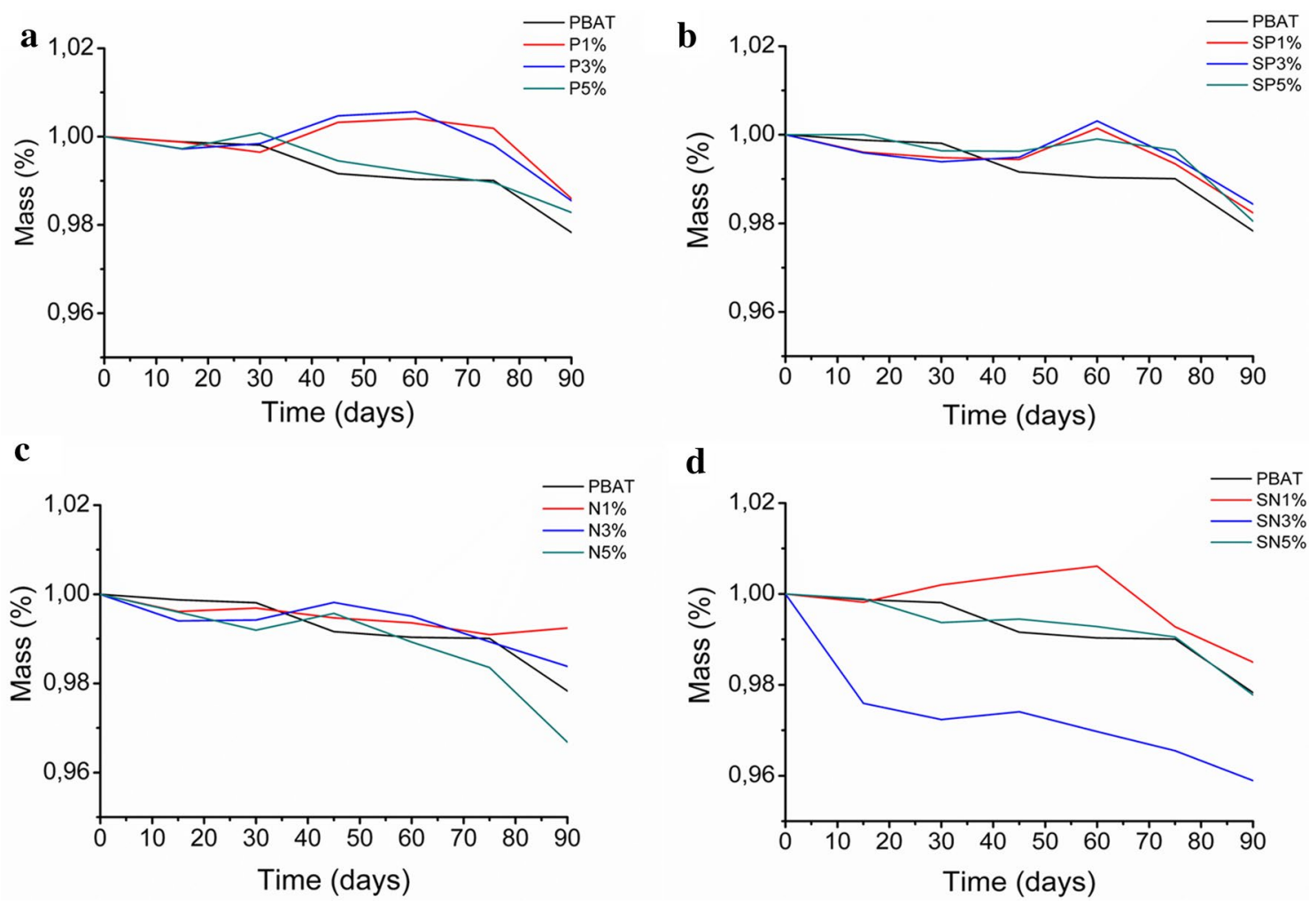

Fig. 7 Simulated degradation in soil measured as mass loss for composites of a P samples, b SP samples, $\mathbf{c}$ N samples, and $\mathbf{d}$ SN samples over 90 days 


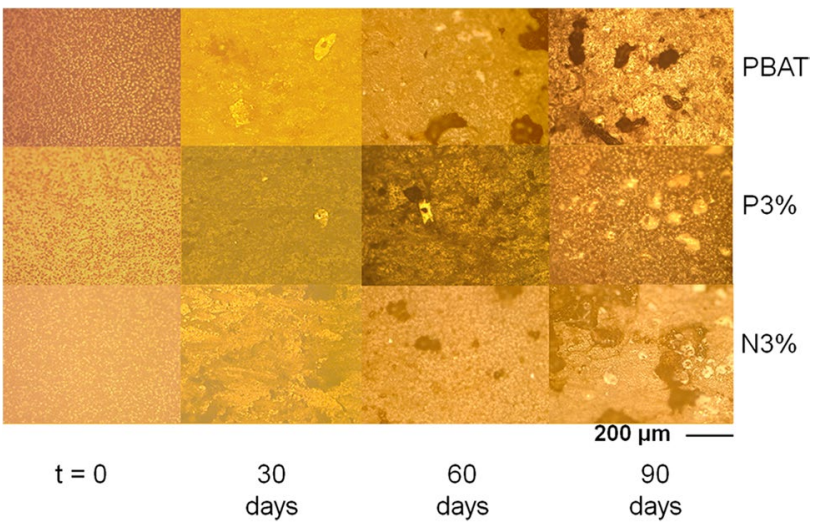

Fig. 8 Photomicrographs at $\times 100$ magnification of a PBAT, b P3\%, and c N3\% samples after 30,60, and 90 days of degradation

lower reinforcement addition presenting lower mass loss than the neat matrix while samples SP3\% and SP5\% presented greater losses, especially sample SN3\%, which degraded more than the matrix.

Besides the mass loss, degradation can also be evaluated by surface characterization, since the abiotic process starts at the material's surface, as reported by Rocha et al. [28]. Optical microscopy was applied to study the surface of the samples every 30 days during degradation. Figure 8 presents photomicrographs of samples P3\% and $\mathrm{N} 3 \%$ and the neat matrix, confirming the formation of pores and the erosion of surface fractions of the samples, which are indications of the abiotic decomposition process of polyesters [66]. In the image obtained after 90 days, the formation of shadows in different forms can be seen on the film's surface, indicating formation of biolayers over the substrate. Therefore, despite the slow rate of degradation, the process of decomposition has already started $[28,63,67]$.

This degradation behavior of the composites indicates that addition of the reinforcement tended to reduce the degradation rate in the long term, suggesting the possibility of controlling the degradation of the polymer and expanding its applications. The $\mathrm{N}$ samples represent a new material due to the low consumption of reagents during production of the nanostructure [26]. The obtained composites offer good mechanical properties together with thermal stability and low degradation. The high contact angle and low water absorption could make such materials an option as raw materials for food packaging that degrades after disposal, avoiding accumulation of waste [42].

\section{Conclusions}

Cellulose nanostructures were obtained by enzymatic hydrolysis, applied directly or after pretreatment, and successfully incorporated into PBAT matrix by a solvent casting method. The mechanical properties of the samples with low reinforcement addition using both methodologies were improved, especially samples $\mathrm{P} 1 \%$ and $\mathrm{N} 1 \%$ with improvements of $12 \%$ and $11 \%$ in the Young's modulus, while addition of surfactant did not improve these properties. The thermal resistance of the matrix was improved for all reinforcements, with an increase of $10{ }^{\circ} \mathrm{C}$ for $3 \%$ reinforcement addition. The affinity of the matrix towards water was reduced, increasing the contact angle and reducing the water absorbed, for both samples without surfactant. However, addition of surfactant resulted in the opposite effect. Addition of the reinforcements promoted a reduction in the degradation rate of the matrix, while addition of surfactant tended to promote the degradation. However, the degradation did not surpass that of the neat matrix in either case. The measured properties indicate that addition of both cellulose nanostructures $(P$ and $\mathrm{N}$ ) resulted in similar properties, indicating that the pretreatment process is not necessary and that $\mathrm{N}$ samples represent a viable choice. Addition of surfactant degraded the mechanical properties but improved the water interaction, enabling the properties of such PBAT composites to be tailored to form versatile materials for use in packaging applications.

Acknowledgements The authors would like to thank UFABC, the institution's multiuser center, the REVALORES Research Center, CNPq (projects no. 306401/2013-4, 447180/2014-2, and 163593/2015-9), and São Paulo Foundation for Research Support (FAPESP) (process no. 2016/12700-5 and 2018/11277-7).

\section{Compliance with ethical standards}

Conflict of interest On behalf of all authors, the corresponding author states that there are no conflicts of interest.

\section{References}

1. Geyer R, Jambeck JR, Law KL (2017) Production, use, and fate of all plastics ever made. Sci Adv 3:e1700782. https://doi. org/10.1126/sciadv.1700782

2. Hoegh-Guldberg O., Cai R., Poloczanska ES., et al (2015) The ocean. Clim Chang 2014 Impacts, Adapt Vulnerability Part B Reg Asp Work Gr II Contrib to Fifth Assess Rep Intergov Panel Clim Chang 1655-1734. https://doi.org/10.1017/CBO978110741538 6.010

3. Papadopoulou E, Chrissafis K (2017) Particleboards from agricultural lignocellulosics and biodegradable polymers prepared with raw materials from natural resources. In: Lau AK, Hung AP-Y 
(eds) Biodegradable and bioresorbable polymer composites. Elsevier, Cambridge, pp 19-30

4. Laycock B, Nikolić M, Colwell JM et al (2017) Lifetime prediction of biodegradable polymers. Prog Polym Sci 71:144-189. https ://doi.org/10.1016/j.progpolymsci.2017.02.004

5. Kargarzadeh H, Mariano M, Huang J et al (2017) Recent developments on nanocellulose reinforced polymer nanocomposites: a review. Polym (United Kingdom) 132:368-393. https://doi. org/10.1016/j.polymer.2017.09.043

6. Zhang X, Ma P, Zhang Y (2016) Structure and properties of surface-acetylated cellulose nanocrystal/poly(butylene adipate-coterephthalate) composites. Polym Bull 73:2073-2085. https:// doi.org/10.1007/s00289-015-1594-y

7. Hubbe MA, Ferrer A, Tyagi P, et al (2017) Nanocellulose in thin films, coatings, and plies for packaging applications: A review. BioResources 12:2143-2233. https://doi.org/10.15376/biore S.12.1.2143-2233

8. Chi K, Catchmark JM (2017) Enhanced dispersion and interface compatibilization of crystalline nanocellulose in polylactide by surfactant adsorption. Cellulose 24:4845-4860. https://doi. org/10.1007/s10570-017-1479-3

9. Abitbol T, Rivkin A, Cao Y et al (2016) Nanocellulose, a tiny fiber with huge applications. Curr Opin Biotechnol 39:76-88. https:// doi.org/10.1016/j.copbio.2016.01.002

10. Habibi $Y$ (2014) Key advances in the chemical modification of nanocelluloses. Chem Soc Rev 43:1519-1542. https://doi. org/10.1039/C3CS60204D

11. Maia THS, Larocca NM, Beatrice CAG et al (2017) Polyethylene cellulose nanofibrils nanocomposites. Carbohydr Polym 173:50 56. https://doi.org/10.1016/j.carbpol.2017.05.089

12. de Lima GF, de Souza AG, Rosa DS (2018) Effect of adsorption of polyethylene glycol (PEG), in aqueous media, to improve cellulose nanostructures stability. J Mol Liq 268:415-424. https:// doi.org/10.1016/j.molliq.2018.07.080

13. Tardy BL, Yokota S, Ago M et al (2017) Nanocellulose-surfactant interactions. Curr Opin Colloid Interface Sci 29:57-67. https:// doi.org/10.1016/j.cocis.2017.02.004

14. Islam MN, Rahman F (2018) Production and modification of nanofibrillated cellulose composites and potential applications. Elsevier, Amsterdam

15. Araújo RS, Ferreira LC, Rezende CC et al (2018) Poly(lactic acid)/ cellulose composites obtained from modified cotton fibers by successive acid hydrolysis. J Polym Environ 0:1-10. https://doi. org/10.1007/s10924-018-1198-3

16. Wang $G$, Yang $X$, Wang W (2019) Reinforcing linear low-density polyethylene with surfactant-treated microfibrillated cellulose. Polymers (Basel) 11:441. https://doi.org/10.3390/polym 11030 441

17. Heux L, Chauve G, Bonini C (2000) Nonflocculating and chiralnematic self-ordering of cellulose microcrystals suspensions in nonpolar solvents. Langmuir 16:8210-8212. https://doi. org/10.1021/la9913957

18. Pinheiro IF, Ferreira FV, Souza DHS et al (2017) Mechanical, rheological and degradation properties of PBAT nanocomposites reinforced by functionalized cellulose nanocrystals. Eur Polym J 97:356-365. https://doi.org/10.1016/j.eurpolymj.2017.10.026

19. Luzi F, Fortunati $E$, Jiménez $A$ et al (2017) PLA nanocomposites reinforced with cellulose nanocrystals from Posidonia oceanica and $\mathrm{ZnO}$ nanoparticles for packaging application. J Renew Mater 5:103-115. https://doi.org/10.7569/JRM.2016.634135

20. Şen F, Gökagaç G (2007) Activity of carbon-supported platinum nanoparticles toward methanol oxidation reaction: role of metal precursor and a new surfactant, tert-octanethiol. J Phys Chem C 111:1467-1473. https://doi.org/10.1021/jp065809y

21. Şen F, Gökağaç G (2008) Improving catalytic efficiency in the methanol oxidation reaction by inserting $\mathrm{Ru}$ in face-centered cubic Pt nanoparticles prepared by a new surfactant, tert-octanethiol. Energy Fuels 22:1858-1864. https://doi. org/10.1021/ef700575t

22. Şen $F$, Şen $S$, Gökağaç G (2011) Efficiency enhancement of methanol/ethanol oxidation reactions on Pt nanoparticles prepared using a new surfactant, 1,1-dimethyl heptanethiol. Phys Chem Chem Phys 13:1676-1684. https://doi. org/10.1039/c0cp01212b

23. Zhu G, Lin N (2019) Surface chemistry of nanocellulose. In: Huang J, Dufresne A, Lin N (eds) Nanocellulose: from fundamentals to advanced materials. Wiley-VCH Verlag, Weinheim

24. Benhalima T, Ferfera-Harrar H (2019) Eco-friendly porous carboxymethyl cellulose/dextran sulfate composite beads as reusable and efficient adsorbents of cationic dye methylene blue. Int J Biol Macromol 132:126-141. https://doi.org/10.1016/j.ijbio mac.2019.03.164

25. Karim Z, Afrin S, Husain Q, Danish R (2017) Necessity of enzymatic hydrolysis for production and functionalization of nanocelluloses. Crit Rev Biotechnol 37:355-370. https://doi. org/10.3109/07388551.2016.1163322

26. Bauli CR, Rocha DB, de Oliveira SA, Rosa DS (2019) Cellulose nanostructures from wood waste with low input consumption. J Clean Prod 211:408-416. https://doi.org/10.1016/j.jclep ro.2018.11.099

27. Mariano M, El Kissi N, Dufresne A (2014) Cellulose nanocrystals and related nanocomposites: review of some properties and challenges. J Polym Sci Part B Polym Phys 52:791-806. https:// doi.org/10.1002/polb.23490

28. Rocha DB, Souza de Carvalho J, de Oliveira SA, dos Santos Rosa D (2018) A new approach for flexible PBAT/PLA/CaCO films into agriculture. J Appl Polym Sci 135. https://doi.org/10.1002/ app. 46660

29. Van Dyk JS, Pletschke BI (2012) A review of lignocellulose bioconversion using enzymatic hydrolysis and synergistic cooperation between enzymes-Factors affecting enzymes, conversion and synergy. Biotechnol Adv 30:1458-1480. https://doi. org/10.1016/j.biotechadv.2012.03.002

30. Lindman B, Karlström G, Stigsson L (2010) On the mechanism of dissolution of cellulose. J Mol Liq 156:76-81. https://doi. org/10.1016/j.molliq.2010.04.016

31. Hu Z, Cranston ED, Ng R, Pelton R (2014) Tuning cellulose nanocrystal gelation with polysaccharides and surfactants. Langmuir 30:2684-2692. https://doi.org/10.1021/la404977t

32. Sameni J, Krigstin S, Sain M (2017) Solubility of lignin and acetylated lignin in organic solvents. BioResources 12:1548-1565

33. Smith RJ, Lotya M, Coleman JN (2010) The importance of repulsive potential barriers for the dispersion of graphene using surfactants. New J Phys 12:125008. https://doi.org/10.1088/13672630/12/12/125008

34. Fortunati E, Armentano I, Zhou Q, et al (2012) Microstructure and nonisothermal cold crystallization of PLA composites based on silver nanoparticles and nanocrystalline cellulose. In: Polymer Degradation and Stability. Elsevier, pp 2027-2036

35. Agarwal B, Ahluwalia V, Pandey A et al (2017) Sustainable production of chemicals and energy fuel precursors from lignocellulosic fractions. In: Agarwal AK, Agarwal RA, Gupta T, Gurjar BR (eds) Biofuels: technology, challenges and prospects. Springer, Singapore, pp 7-33

36. Claro P, de Campos A, Corrêa A et al (2019) Curaua and eucalyptus nanofiber films by continuous casting: mixture of cellulose nanocrystals and nanofibrils. Cellulose 9:2453-2470. https://doi. org/10.1007/s10570-019-02280-9

37. Claro PIC, Corrêa AC, de Campos A et al (2018) Curaua and eucalyptus nanofibers films by continuous casting: mechanical and thermal properties. Carbohydr Polym 181:1093-1101. https:// doi.org/10.1016/j.carbpol.2017.11.037 
38. Morelli CL, Belgacem MN, Branciforti MC et al (2016) Supramolecular aromatic interactions to enhance biodegradable film properties through incorporation of functionalized cellulose nanocrystals. Compos Part A 83:80-88. https://doi. org/10.1016/j.compositesa.2015.10.038

39. Espino-Pérez E, Bras J, Ducruet V et al (2013) Influence of chemical surface modification of cellulose nanowhiskers on thermal, mechanical, and barrier properties of poly(lactide) based bionanocomposites. Eur Polym J 49:3144-3154. https://doi. org/10.1016/j.eurpolymj.2013.07.017

40. Kim J, Montero G, Habibi Y et al (2009) Dispersion of cellulose crystallites by nonionic surfactants in a hydrophobic polymer matrix. Polym Eng Sci 49:2054-2061. https://doi.org/10.1002/ pen

41. Sudhakaran Nair S, Chen H, Peng $Y$ et al (2018) Polylactic acid biocomposites reinforced with nanocellulose fibrils with high lignin content for improved mechanical, thermal and barrier properties. ACS Sustain Chem Eng. https://doi.org/10.1021/ acssuschemeng.8b01405

42. Tavares LB, Ito NM, Salvadori MC et al (2018) PBAT/kraft lignin blend in flexible laminated food packaging: peeling resistance and thermal degradability. Polym Test 67:169-176. https://doi. org/10.1016/j.polymertesting.2018.03.004

43. Mukherjee T, Czaka M, Kao N et al (2014) Dispersion study of nanofibrillated cellulose based poly(butylene adipate-co-terephthalate) composites. Carbohydr Polym 102:537-542. https:// doi.org/10.1016/j.carbpol.2013.11.047

44. Muniyasamy S, Reddy MM, Misra M, Mohanty A (2013) Biodegradable green composites from bioethanol co-product and poly(butylene adipate-co-terephthalate). Ind Crops Prod 43:812-819. https://doi.org/10.1016/j.indcrop.2012.08.031

45. Khoo RZ, Ismail H, Chow WS (2016) Thermal and morphological properties of poly (lactic acid)/nanocellulose nanocomposites. Proc Chem 19:788-794. https://doi.org/10.1016/j.proch e.2016.03.086

46. Essabir H, Bensalah MO, Rodrigue D et al (2016) Structural, mechanical and thermal properties of bio-based hybrid composites from waste coir residues: fibers and shell particles. Mech Mater 93:134-144. https://doi.org/10.1016/j.mechm at.2015.10.018

47. Scaffaro R, Maio A, Sutera F et al (2019) Degradation and recycling of films based on biodegradable polymers: a short review. Polymers (Basel) 11:651. https://doi.org/10.3390/polym 11040 651

48. Pinheiro IF, Ferreira FV, Alves GF et al (2019) Biodegradable PBATbased nanocomposites reinforced with functionalized cellulose nanocrystals from Pseudobombax munguba: rheological, thermal, mechanical and biodegradability properties. J Polym Environ 27:757-766. https://doi.org/10.1007/s10924-019-01389-z

49. de Macedo JRN, dos Santos Rosa D (2015) Effect of fiber and starch incorporation in biodegradation of PLA-TPS-cotton composites. Key Eng Mater 668:54-62. https://doi.org/10.4028/ www.scientific.net/KEM.668.54

50. Yuan Y, Lee TR (2013) Contact angle and wetting properties. In: Bracco G, Holst B (eds) Surface science techniques. Springer, Berlin, pp 3-34

51. Rojo E, Peresin MS, Sampson WW et al (2015) Comprehensive elucidation of the effect of residual lignin on the physical, barrier, mechanical and surface properties of nanocellulose films. Green Chem 17:1853-1866. https://doi.org/10.1039/c4gc02398f

52. Moustafa H, Guizani C, Dupont $C$ et al (2017) Utilization of torrefied coffee grounds as reinforcing agent to produce highquality biodegradable PBAT composites for food packaging applications. ACS Sustain Chem Eng 5:1906-1916. https://doi. org/10.1021/acssuschemeng.6b02633

53. Fortunati E, Gigli M, Luzi F et al (2017) Processing and characterization of nanocomposite based on poly(butylene/triethylene

SN Applied Sciences succinate) copolymers and cellulose nanocrystals. Carbohydr Polym 165:51-60. https://doi.org/10.1016/j.carbpol.2017.02.024

54. Feng J, Nguyen ST, Fan Z, Duong HM (2015) Advanced fabrication and oil absorption properties of super-hydrophobic recycled cellulose aerogels. Chem Eng J 270:168-175. https://doi. org/10.1016/j.cej.2015.02.034

55. Luz AP, Ribeiro S, Pandolfelli VC (2008) Uso da molhabilidade na investigação do comportamento de corrosão de materiais refratários. Cerâmica 54:174-183. https://doi.org/10.1590/S0366 $-69132008000200007$

56. Wang W, Zhuang X, Tan X et al (2018) Dual effect of nonionic surfactants on improving the enzymatic hydrolysis of lignocellulose. Energy Fuels 32:5951-5959. https://doi.org/10.1021/acs. energyfuels.8b00225

57. Solala I, Bordes R, Larsson A (2017) Water vapor mass transport across nanofibrillated cellulose films: effect of surface hydrophobization. Cellulose. https://doi.org/10.1007/s10570-017-1608-z

58. Espert A, Vilaplana F, Karlsson S (2004) Comparison of water absorption in natural cellulosic fibres from wood and one-year crops in polypropylene composites and its influence on their mechanical properties. Compos Part A Appl Sci Manuf 35:12671276. https://doi.org/10.1016/j.compositesa.2004.04.004

59. Smita Mohanty MC (2015) Effect of different solvents in solvent casting of porous scaffolds-in biomedical and tissue engineering applications. J Tissue Sci Eng 06:1-7. https://doi. org/10.4172/2157-7552.1000142

60. Liu Y, Soer WJ, Scheerder J et al (2015) Water vapor sorption and diffusion in secondary dispersion barrier coatings: a critical comparison with emulsion polymers. ACS Appl Mater Interfaces 7:12147-12157. https://doi.org/10.1021/acsami.5b02446

61. Aramendia E, Barandiaran MJ, Grade J et al (2005) Improving water sensitivity in acrylic films using surfmers. Langmuir 21:1428-1435. https://doi.org/10.1021/la047631 h

62. Kijchavengkul T, Auras R, Rubino M et al (2010) Biodegradation and hydrolysis rate of aliphatic aromatic polyester. Polym Degrad Stab 95:2641-2647. https://doi.org/10.1016/j.polym degradstab.2010.07.018

63. Weng YX, Jin YJ, Meng QY et al (2013) Biodegradation behavior of poly(butylene adipate-co-terephthalate) (PBAT), poly(lactic acid) (PLA), and their blend under soil conditions. Polym Test 32:918-926. https://doi.org/10.1016/j.polymertes ting.2013.05.001

64. Spaccini R, Todisco D, Drosos M et al (2016) Decomposition of bio-degradable plastic polymer in a real on-farm composting process. Chem Biol Technol Agric 3:1-12. https://doi. org/10.1186/s40538-016-0053-9

65. Singh G, Chandoha-Lee C, Zhang W et al (2016) Biodegradation of nanocrystalline cellulose by two environmentally-relevant consortia. Water Res 104:137-146. https://doi.org/10.1016/j. watres.2016.07.073

66. Rodrigues CA, Tofanello A, Nantes IL, Rosa DS (2015) Biological oxidative mechanisms for degradation of poly(lactic acid) blended with thermoplastic starch. ACS Sustain Chem Eng 3:2756-2766. https://doi.org/10.1021/acssuschemeng.5b00639

67. Zumstein MT, Schintlmeister A, Nelson TF et al (2018) Biodegradation of synthetic polymers in soils: tracking carbon into $\mathrm{CO}_{2}$ and microbial biomass. Sci Adv 4:1-8. https://doi.org/10.1126/ sciadv.aas 9024

Publisher's Note Springer Nature remains neutral with regard to jurisdictional claims in published maps and institutional affiliations. 